University of Nebraska - Lincoln

DigitalCommons@University of Nebraska - Lincoln

Alexei Gruverman Publications

Research Papers in Physics and Astronomy

August 1999

\title{
Switching properties of self-assembled ferroelectric memory cells
}

M. Alexe

Max Planck Institute of Microstructure Physics, Weinberg 2, Germany

Alexei Gruverman

University of Nebraska-Lincoln, agruverman2@unl.edu

C. Harnagea

Max Planck Institute of Microstructure Physics, Weinberg 2, D-06120 Halle (Saale), Germany

N. D. Zakharov

Max Planck Institute of Microstructure Physics, Weinberg 2, D-06120 Halle (Saale), Germany

A. Pignolet

Max Planck Institute of Microstructure Physics, Weinberg 2, D-06120 Halle (Saale), Germany

See next page for additional authors

Follow this and additional works at: https://digitalcommons.unl.edu/physicsgruverman

Part of the Physics Commons

Alexe, M.; Gruverman, Alexei; Harnagea, C.; Zakharov, N. D.; Pignolet, A.; Hesse, D.; and Scott, J. F., "Switching properties of self-assembled ferroelectric memory cells" (1999). Alexei Gruverman Publications. 5.

https://digitalcommons.unl.edu/physicsgruverman/5

This Article is brought to you for free and open access by the Research Papers in Physics and Astronomy at DigitalCommons@University of Nebraska - Lincoln. It has been accepted for inclusion in Alexei Gruverman Publications by an authorized administrator of DigitalCommons@University of Nebraska - Lincoln. 
Authors

M. Alexe, Alexei Gruverman, C. Harnagea, N. D. Zakharov, A. Pignolet, D. Hesse, and J. F. Scott 


\title{
Switching properties of self-assembled ferroelectric memory cells
}

\author{
M. Alexe ${ }^{\mathrm{a})}$ \\ Max Planck Institute of Microstructure Physics, Weinberg 2, D-06120 Halle (Saale), Germany \\ A. Gruverman \\ Frontier Science Laboratories, Sony Corporation, 134 Godo-cho, Hodogaya, Yokohama-shi, \\ 240-0005, Japan \\ C. Harnagea, N. D. Zakharov, A. Pignolet, and D. Hesse \\ Max Planck Institute of Microstructure Physics, Weinberg 2, D-06120 Halle (Saale), Germany \\ J. F. Scott \\ School of Physics, University of New South Wales, Sydney 2052, Australia
}

(Received 26 April 1999; accepted for publication 25 June 1999)

\begin{abstract}
In this letter, we report on the switching properties of an ordered system of $\mathrm{Bi}_{4} \mathrm{Ti}_{3} \mathrm{O}_{12}$ ferroelectric memory cells of an average lateral size of $0.18 \mu \mathrm{m}$ formed via a self-assembling process. The ferroelectricity of these cells has been measured microscopically and it has been demonstrated that an individual cell of $0.18 \mu \mathrm{m}$ size is switching. Switching of single nanoelectrode cells was achieved via scanning force microscopy working in piezoresponse mode. (C) 1999 American
\end{abstract} Institute of Physics. [S0003-6951(99)00334-4]

Ferroelectric thin-film random access memories (FeRAMs) are at present in commercial production in lowdensity embedded devices as large as 64 kbit for "smart" credit/debit cards ${ }^{1}$ or household electrical appliances ${ }^{2}$ and as large as 1 Mbit for free-standing (nonembedded) memories. ${ }^{3}$ The smallest switching single cells reported to date are of sizes $1.0 \times 1.0 \mu \mathrm{m}$ from Mitsubishi-Symetrix, ${ }^{4} 0.7 \times 0.7 \mu \mathrm{m}$ from $\mathrm{NEC}^{5}$ and $0.1 \times 0.1 \mu \mathrm{m}$ from MPI-Halle. ${ }^{6}$ Here, we report on the switching properties of a system of 0.18 $\times 0.18 \mu \mathrm{m}$ cells made via a self-assembling process and on the hysteretic switching of these cells, which are made out of layer-structure perovskite bismuth titanate, $\mathrm{Bi}_{4} \mathrm{Ti}_{3} \mathrm{O}_{12}(\mathrm{BiT})$, thin films epitaxially grown on $\mathrm{SrTiO}_{3}$ single crystalline substrates.

We previously described ${ }^{7}$ rectangular planar arrays of Bi-containing crystalline electrodes showing metallic conductivity ("nanoelectrodes") obtained on the surface of epitaxial films of BiT prepared by pulsed laser deposition (PLD). The bismuth titanate film had been deposited on the top of an epitaxial layer of $\mathrm{La}_{0.5} \mathrm{Sr}_{0.5} \mathrm{CoO}_{3}$ (LSCO) serving both as electrode and as template for the ferroelectric film. An epitaxial layer of $\mathrm{CeO}_{2}$ and an underlying epitaxial yttrium-stabilized zirconia (YSZ) layer between the LSCO and the $\mathrm{Si}$ substrate prevent $\mathrm{Bi}$ diffusion. The nanoelectrodes, yielding 1 Gbit of accessible ferroelectric cells per chip $\left(\sim 0.5 \times 0.5 \mathrm{~cm}^{2}\right)$, are uniform and well separated from each other with no overlap or terraces. Depending upon processing conditions the size of the nanoelectrodes is typically $150 \mathrm{~nm}$ and can exceed $200 \mathrm{~nm}$. They are mainly composed of crystalline cubic $\delta$ - $\mathrm{Bi}_{2} \mathrm{O}_{3}$ as determined from highresolution electron microscopy (HREM). Cubic $\delta$ - $\mathrm{Bi}_{2} \mathrm{O}_{3}$ has a defect fluorite structure and is the best ion-conductor known, with a resistivity of $1 \Omega \mathrm{cm}$ at $1023 \mathrm{~K}$. ${ }^{8}$ Switching of a macroscopic collection of these nanocells was achieved in

${ }^{a)}$ Electronic mail: malexe@mpi-halle.de the previous work ${ }^{7}$ probing the samples via $\mathrm{Hg}$ probes. The ferroelectric hysteresis curve obtained and discussed in Ref. 7 was neither square nor saturated having a coercive voltage of about $3 \mathrm{~V}$, corresponding to a field of $55 \mathrm{kV} / \mathrm{cm}$, and a remanent polarization $P_{r}>4 \mu \mathrm{C} / \mathrm{cm}^{2}$. Nevertheless, an important concern is to find out whether a single cell switches or not. Due to the technical limitations, the efforts in acquiring a dielectric hysteresis of a single nanocell were unsuccessful up to now. ${ }^{9}$ In the present letter, we are now able to demonstrate the switching properties of these single nanocells using scanning force microscope (SFM) working in the piezoresponse mode.
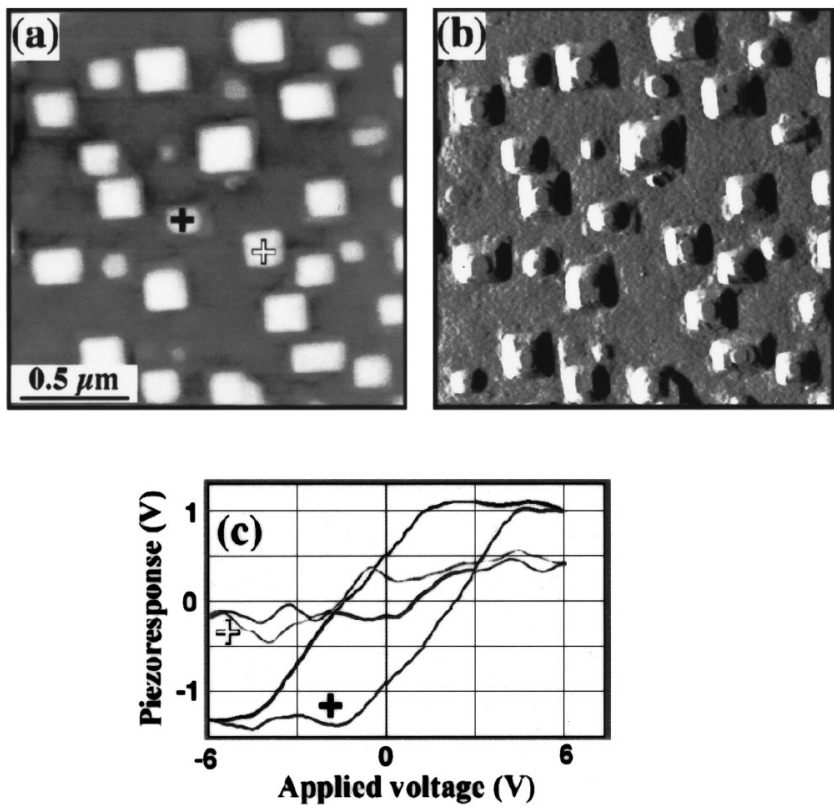

FIG. 1. Topographic images (a) height and (b) amplitude of self-assembled Bi-containing nanoelectrodes forming an array of ferroelectric memory cells on an epitaxial $\mathrm{Bi}_{4} \mathrm{Ti}_{3} \mathrm{O}_{12}$ thin film. (c) Piezoelectric hysteresis of two different cells marked with a white and a black cross, respectively. 

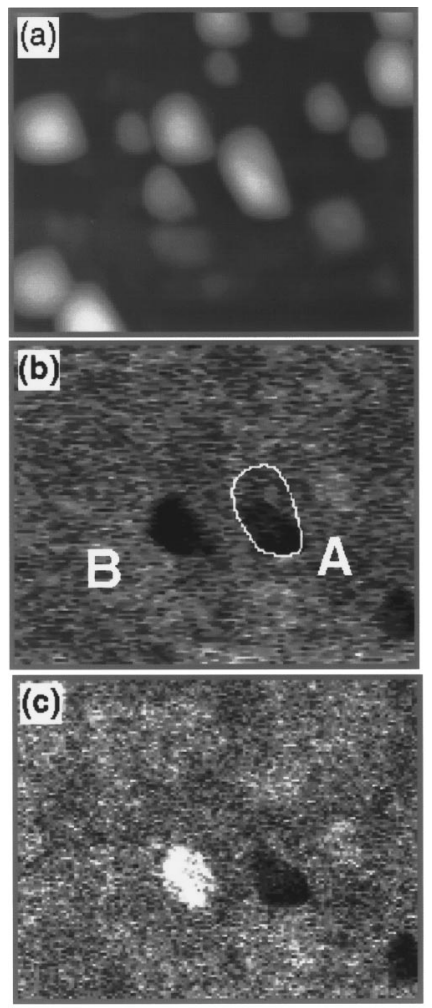

$500 \mathrm{~nm}$

FIG. 2. (a) Topographic and (b), (c) piezoelectric images showing switching of a single memory cell. The contour of the cell marked with " $\mathrm{A}$ " has been determined from the topography image. The cell " $\mathrm{B}$ " is shown (b) before and (c) after applying a single voltage pulse of $+10 \mathrm{~V}$ for $100 \mathrm{~ms}$.

SFM working in the piezoresponse mode is a powerful tool used in characterization of ferroelectric films at the nanometer scale. ${ }^{10,11}$ Briefly, a conductive tip probes the sample surface and a testing ac signal with a frequency in the $\mathrm{kHz}$ range is applied between the tip and the bottom electrode of the sample. Due to the converse piezoelectric effect, the sample underneath the tip mechanically oscillates with the same frequency as the excitation signal and thus generates oscillations of the cantilever. Using a lock-in technique, the piezoelectric signal is extracted from the total deflection signal of the SFM. Hysteresis loops of individual nanocapacitors were recorded by positioning the tip on the top of a selected nanoelectrode and monitoring its piezoresponse signal as a function of a dc (bias) voltage superimposed on a probing (imaging) voltage. Hysteresis in this strain-field loop
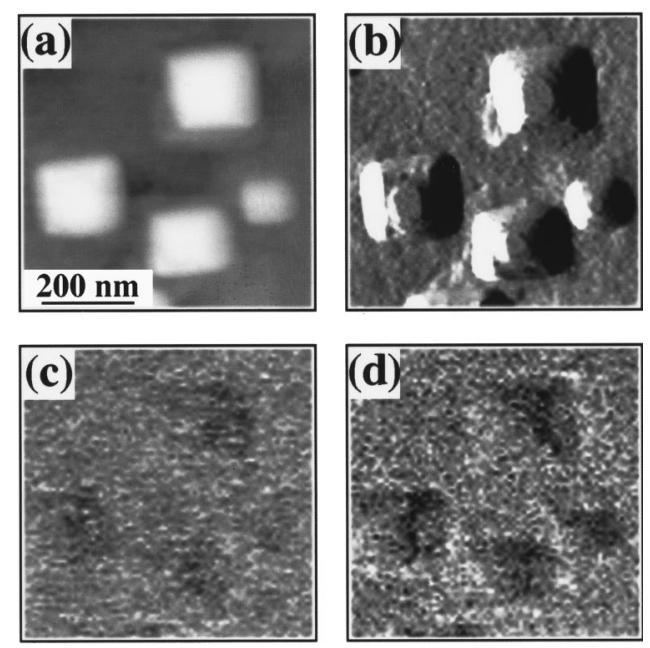

FIG. 3. Topographic images (a) high and (b) amplitude, and piezoelectric images acquired (c) before and (d) after applying switching voltages of -10 $\mathrm{V}$. Note the contrast enhancement revealing a poling process.

is always associated with ferroelectric properties of the sample. $^{12}$

Figures 1(a) and 1(b) show topographic images of an array of $0.18 \times 0.18 \mu \mathrm{m} \delta-\mathrm{Bi}_{2} \mathrm{O}_{3} / \mathrm{BiT}$ cells produced via PLD and Fig. 1(c) illustrates the switching by presenting piezoelectric hysteresis loops obtained via piezoresponse SFM for two different cells. These loops are conclusive evidence of the ferroelectric switching in single nanosize capacitors. However, a marked difference in the piezoelectric signal and the hysteresis loops between the two probed cells can be observed. While the cell marked with the black cross is showing a reasonable hysteresis, the cell marked with the white cross shows a hysteretical behavior but with a low piezoelectric activity. Switching of a single cell is visualized by the piezoresponse images presented in Figs. 2(b) and 2(c). In these piezoresponse images, the white and black contrast are showing the positively $(+P)$ and negatively $(-P)$ polarized domains, respectively. The most left cell [the " $\mathrm{B}$ ", cell in Fig. 2(b)] was switched from the negative state (black) to a positive state (white) by applying a voltage pulse of $+10 \mathrm{~V}$ for $100 \mathrm{~ms}$. Note also that not all cells shown in the topography image [Fig. 2(a)] have an equivalent piezoresponse image in Figs. 2(b) and 2(c). Only a few cells have an intense piezoelectric response while the other cells have a piezoelectric response at or below the noise limit. The cells show no piezoelectric response, and therefore could not

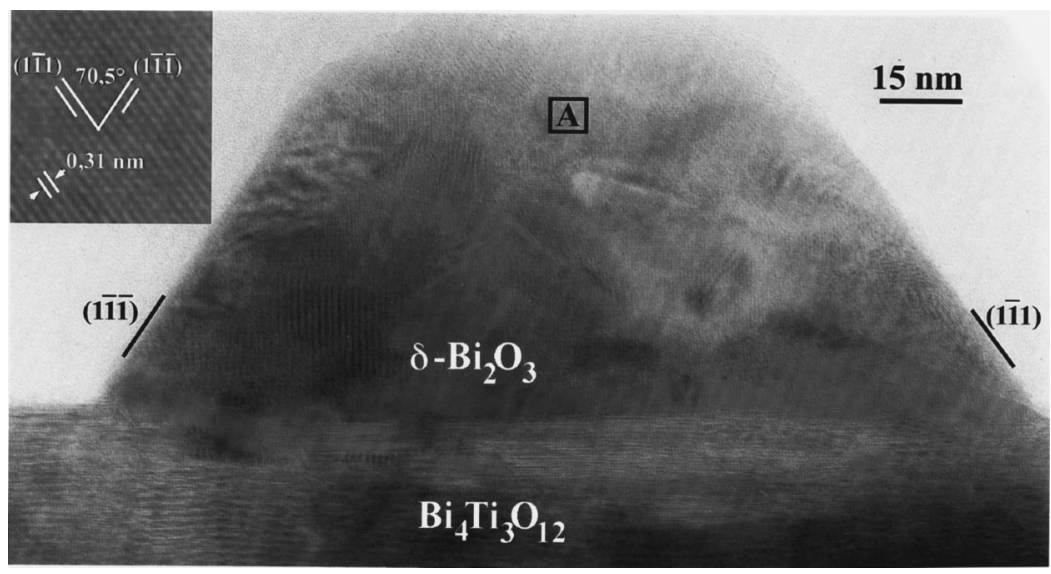

FIG. 4. Cross-section transmission electron microscope image of a single Bi-containing nanoelectrode. The inset shows the region $\mathrm{A}$ at a high magnification and reveals the crystal lattice of $\delta-\mathrm{Bi}_{2} \mathrm{O}_{3}$ in the $\langle 110\rangle$ projection. 
be switched by applying positive voltage pulses as previously shown. This means that they are either not "ferroelectric', or, due to poor conductive properties of the nanoelectrode, the electric fields in the ferroelectric film are too small. This is well shown in Fig. 3 where applying voltage pulses to each cell causes only a contrast enhancement in the piezoresponse image, most probably due to a poling, but does not result in the anticipated switching. This is an unexpected result showing nonuniformity at the nanoscale level of the ferroelectric behavior in the self-patterned $\delta$ - $\mathrm{Bi}_{2} \mathrm{O}_{3} / \mathrm{BiT}$ cells. Several reasons may contribute to this behavior. The epitaxially grown BiT is $c$-oriented, therefore, the ferroelectricity and the associated piezoelectric constant are very low compared with $a$-oriented BiT. Depending on the sample, the thickness of the Bi oxide electrodes is between 20 and $75 \mathrm{~nm}$ and these fairly thick electrodes will mechanically damp the vibration of the BiT film generated by the piezoelectric effect. Both reasons lead to a poor piezoelectric signal (at the noise limit) even in the most favorable cases. Note also in Fig. 2 that only part of the cell marked with "A" exhibits piezoelectric activity. This can suggest nonuniformity within a single cell coming from an inhomogeneity either of the BiT film (existence of small amount of $a$-oriented crystallites) or of the Bi-containing nanoelectrode. X-ray diffraction analysis (not shown here) and transmission electron microscope (TEM) analyses (Fig. 4) showed homogeneous $c$-oriented epitaxial film ruling out the hypothesis of $a$-oriented grains. However, the high-resolution TEM (Fig. 4) showed that the nanoelectrodes themselves are not homogeneous. The amount of the conductive $\delta$ - $\mathrm{Bi}_{2} \mathrm{O}_{3}$ can vary from one nanoelectrode to another and this will have an important influence by lowering the actual electric field in the BiT film thus decreasing the piezoelectric signal.

The fact that nanoscale cells do not switch as single domains was heretofore unknown and indeed unexpected and will complicate the fabrication of FeRAMs using selfassembled $\mathrm{Bi}$ oxide nanoelectrodes, since only approximately 2000 electrons can be switched in such a nanoscale cell provided that the whole cell is switching. The sense amplifiers will consequently have great difficulty to discriminate between $+\operatorname{Pr}$ and $-\operatorname{Pr}$ states of the remanent polarization (a " 1 " and a " 0 " bit in the memory cell) for such partial-cell reversals.

In conclusion, we have demonstrated hysteretic switching in single nanoscale ferroelectric cells that are 50 times smaller than the previous record from NEC. The surprising result is that even $0.18 \times 0.18 \mu \mathrm{m}$ cells do not exhibit singledomain switching, which can be attributed rather to the nonhomogeneity of the $\mathrm{Bi}$ oxide nanoelectrodes than to the pinning of the domain walls empirically related to the electrode thickness. ${ }^{13}$

${ }^{1}$ O. Auciello, J. F. Scott, and R. Ramesh, Phys. Today 51, 22 (1998).

${ }^{2}$ T. Fukushima, A. Kawahara, T. Nanba, M. Matsumoto, T. Nishimoto, N. Ikeda, Y. Judai, T. Sumi, K. Arita, and T. Otsuki, Symposium on VLSI Circuits, Digest of Technical Papers (IEEE Cat. No. 96CH35943) Widerkehr \& Associates, Gaithersburg, 1996, pp. 46-47.

${ }^{3}$ H. Koike, T. Otsuki, T. Kimura, M. Fukuma, Y. Hayashi, Y. Maejima, K. Amantuma, N. Tanabe, T. Masuki, S. Saito, T. Takeuchi, S. Kobayashi, T. Kunio, T. Hase, Y. Miyasaka, N. Shohata, and M. Takada, IEEE J. SolidState Circuits 31, 1625 (1996).

${ }^{4}$ H. Uchida, N. Soyama, K. Kageyama, K. Ogi, M. C. Scott, J. D. Cuchiaro, L. D. McMillan, and C. A. Paz de Araujo, Integr. Ferroelectr. 18, 249 (1997).

${ }^{5}$ K. Ammanuma and T. Kunio, Jpn. J. Appl. Phys., Part 1 35, 5229 (1996).

${ }^{6}$ M. Alexe, C. Harnagea, D. Hesse, and U. Gösele, Appl. Phys. Lett. (in press).

${ }^{7}$ M. Alexe, J. F. Scott, C. Curran, N. D. Zakharov, D. Hesse, and A. Pignolet, Appl. Phys. Lett. 73, 1592 (1998).

${ }^{8}$ T. Takahashi and H. Iwahara, Mater. Res. Bull. 13, 1447 (1978).

${ }^{9}$ The total charge released by a $0.1 \times 0.1 \mu \mathrm{m}^{2}$ cell having $P$ $=2-4 \mu \mathrm{C} / \mathrm{cm}^{2}$ is about 2000 electrons. The extremely low capacitance and high impedance of the sample will prevent to measure this amount of charge without on-chip integrated amplifiers.

${ }^{10}$ K. Franke, J. Besold, W. Haessler, and C. Seefebarth, Surf. Sci. Lett. 302, L283 (1994).

${ }^{11}$ A. Gruverman, O. Auciello, and H. Tokumoto, Integr. Ferroelectr. 19, 49 (1998).

${ }^{12}$ D. Damjanovic, Rep. Prog. Phys. 61, 1267 (1998).

${ }^{13}$ J. F. Scott and B. Pouligny, J. Appl. Phys. 64, 1547 (1988). 